\title{
Changes in Left Ventricular Dimensions after Pulmonary Artery Banding and Jatene Operation in Children with Complete Transposition of the Great Arteries
}

\author{
Echocardiographic Study
}

\author{
Kan Tooyama, M.D., Gengi Satomi, M.D., \\ Makoto Nakazawa, M.D., Masashi Seguchi, M.D., \\ Kazuhiro Mori, M.D., Atsuyoshi TaKaO, M.D., \\ and Yasuharu ImaI, M.D.
}

\section{SUMMARY}

Echocardiographic left ventricular (LV) dimensions in patients with complete transposition of the great arteries (TGA's) were measured before and after the Jatene procedure and/or pulmonary artery banding (PAB). The LV posterior wall thickness at end-diastole (LVPWTD) increased from $3.5 \pm 0.4$ to $4.9 \pm 0.9 \mathrm{~mm}($ mean $\pm 1 \mathrm{SD})(\mathrm{p}<0.01)$ after $\mathrm{PAB}$, but it did not show a significant change following the Jatene procedure (from $4.5 \pm 1.0$ to $5.3 \pm 0.8 \mathrm{~mm})$. The $\mathrm{LV}$ end-diastolic internal dimension (LVIDD) increased from $17.7 \pm 4.0$ to $22.6 \pm 6.5 \mathrm{~mm}$ after PAB $(p<0.01)$, but remained unchanged after the Jatene procedure (from $24.5 \pm 5.0$ to $25.0 \pm 3.0 \mathrm{~mm}$ ). The LV shortening fraction (LVSF) decreased from $0.62 \pm 0.10$ to $0.47 \pm 0.14$ after $\mathrm{PAB}(\mathrm{p}<0.01)$, but remained unchanged after the Jatene procedure $(0.40 \pm 0.10$ to $0.37 \pm 0.10)$. The $\mathrm{a} / \mathrm{b}$ ratio at end-systole: $(\mathrm{a} / \mathrm{b}) \mathrm{s}$, which indicates the flatness of the $\mathrm{LV}$ configuration, increased from $0.27 \pm 0.14$ to $0.60 \pm 0.21$ after $\mathrm{PAB}(\mathrm{p}<0.01)$ and from $0.61 \pm 0.13$ to $0.74 \pm 0.17$ after the Jatene procedure $(\mathrm{p}<0.01)$. The data obtained became stable 1 month after operation. One patient died of low cardiac output with no evidence of myocardial infarction after the Jatene procedure. In this patient, LVPWTD was $5.7 \mathrm{~mm}$, LVIDD was $26 \mathrm{~mm}, \mathrm{LVSF}$ was 0.71 and the $(\mathrm{a} / \mathrm{b}) \mathrm{s}$ ratio was 0.55 .

In conclusion, PAB effectively increases $\mathrm{LV}$ wall thickness 1 month after operation, and echocardiographic prerequisites for the Jatene procedure were LVPWTD $>4.0 \mathrm{~mm}$, $(\mathrm{a} / \mathrm{b}) \mathrm{s}$ ratio $>0.5$, and LVSF between 0.2 and 0.56 in patients younger than 16 months.

From the Department of Pediatrics, Doai Memorial Hospital, Departments of Pediatric Cardiology and Pediatric Cardiovascular Surgery, The Heart Institute of Japan, Tokyo Women's Medical College, Tokyo.

Address for reprints: Kan Tooyama, M.D., Department of Pediatrics, Doai Memorial Hospital, 2-1-11 Yokoami-cho, Sumida-ku, Tokyo 130, Japan.

Received for publication November 26, 1986.

Accepted February 12, 1988. 


\section{Additional Indexing Words:}

Complete transposition of the great arteries Jatene operation Echocardiographic left ventricular dimensions

N complete transposition of the great arteries (TGA's), the Jatene procedure can be successfully performed only in patients with a left ventricle which is anatomically and functionally capable of supporting the high pressure of the systemic circulation. The conditions are naturally satisfied in cases with a large ventricular septal defect. In cases with an intact ventricular septum, pulmonary artery banding is done to increase left ventricular (LV) pressure." The effects of this palliative procedure on LV dimensions and function are not well known and it is essential to evaluate them before the arterial switch operation. Therefore, echocardiographic LV dimensions were studied before and after pulmonary artery banding in complete TGA's with an intact ventricular septum. In addition, those parameters were also studied in patients who underwent the Jatene procedure in order to determine the prerequisites for successful repair.

\section{Subjects and Methods}

Subjects consisted of 2 major groups. One group included 14 patients who underwent pulmonary artery banding with Blalock-Taussig anastomosis. Age at the time of operation ranged from 2 to 14 months with a mean of 6.7 months. The other group included 17 patients who underwent a Lecompte modification of the arterial switch operation ${ }^{2)}$ at between 3 months and 6 years of age, mean of 13.8 months. Two patients in the latter group had significant aortic regurgitation after surgery. These 2 were excluded from the statistical analysis of postoperative data, because LV dimensions may be influenced by severe left ventricular volume overload. In 10 patients, serial changes were observed through pulmonary artery banding and the arterial switch operation.

Echocardiographic measurements of LV dimensions were done according to the recommendations of the American Society of Echocardiography. ${ }^{3)}$ To evaluate $\mathrm{LV}$ pressure in the short-axis view of the left ventricle at the level of the papillary muscle on two-dimensional echocardiography, we measured the ratio of the distance between the two septoparietal junctions (designated as b) to the septal to posterior free wall distance (a) at end-systole and expressed it as $\left.(\mathrm{a} / \mathrm{b}) \mathrm{s}^{4}\right)$ The instrument used was a Toshiba SSH-11A with a 2.4 or $5.0 \mathrm{MHz}$ transducer.

Since the ages of the subjects were distributed within a narrow range 
except for one 6 year old patient, the data were not normalized. The mean values are expressed as mean \pm standard deviation (SD) and were analyzed by the paired t-test.

\section{Results}

In cases of pulmonary artery banding, the end-diastolic $\mathrm{LV}$ posterior wall thickness increased rather quickly in the first month following surgery and continued to increase very slowly thereafter. After the Jatene procedure it reached a maximum value from the 5 th to 10 th postopcrative day following which it decreased slightly and then became constant 1 month after operation (Fig. 1). Based upon these observations, the latest data were used for the pulmonary artery banding group and the data at 1 month after operation for the Jatene operation group.

The LV posterior wall thickness at end-diastole increased after pulmonary artery banding from $3.5 \pm 0.4 \mathrm{~mm}$ (mean $\pm 1 \mathrm{SD}$ ) to $4.9 \pm 0.9 \mathrm{~mm}$ but it did not show a significant change after the Jatene procedure (from $4.5 \pm 1.0$ to $5.3 \pm 0.8 \mathrm{~mm}$ ) (Fig. 2).

The LV end-diastolic internal dimension (LVIDD) increased from 17.7 \pm 4.0 to $22.6 \pm 6.5 \mathrm{~mm}$ after pulmonary artery banding, but remained un-

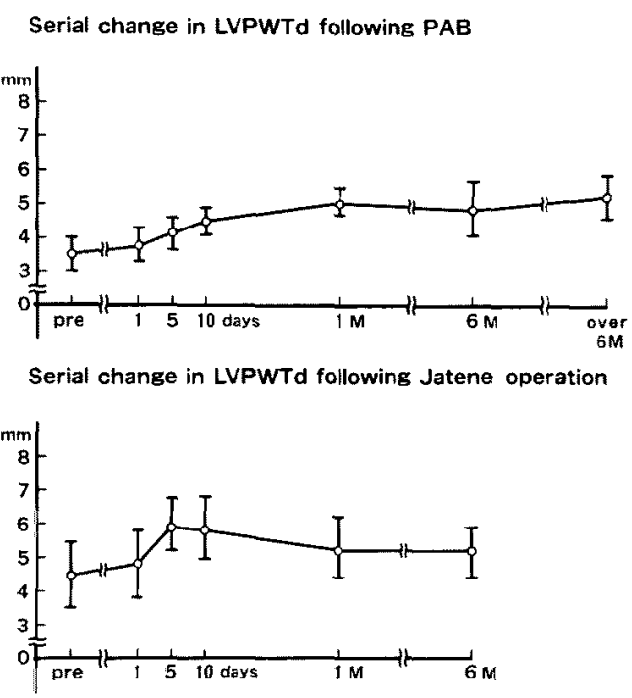

Fig. 1. Serial changes in left ventricular posterior wall thickness at enddiastole (LVPWTD) following pulmonary artery banding (PAB) and Jatene operation. This parameter became constant 1 month after either procedure. pre $=$ preoperation. $\phi:$ mean \pm 1 ISD. 

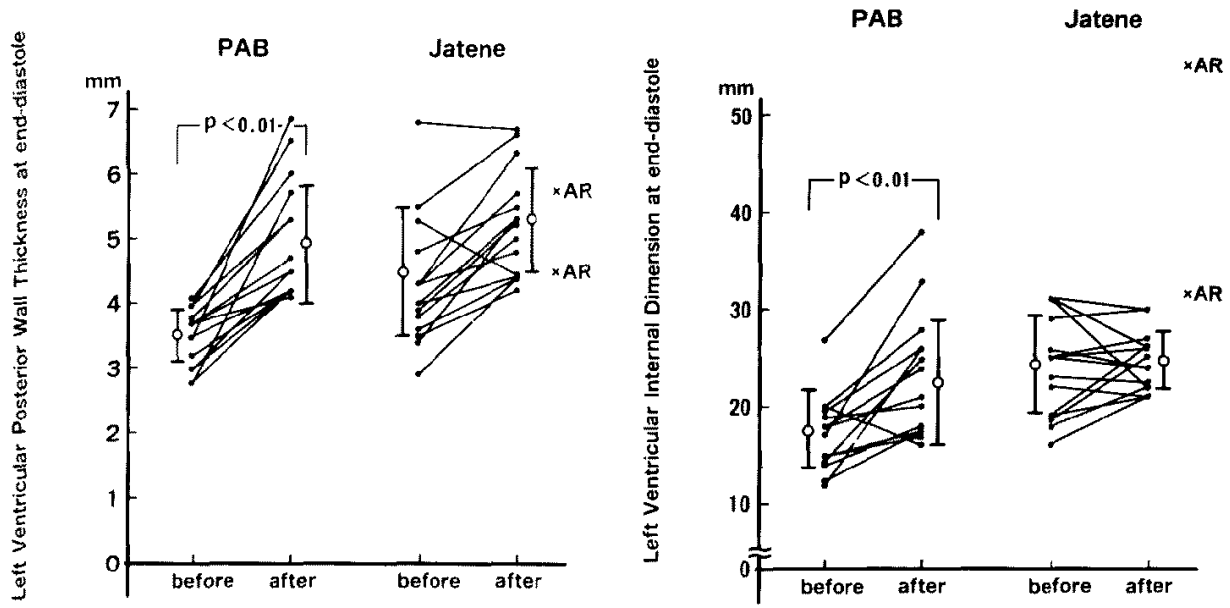

Fig. 2 (left). The diastolic left ventricular posterior wall thickness increased after pulmonary artery banding (PAB), but did not significantly change after Jatene operation. $\quad=$ mean $\pm 1 \mathrm{SD},{ }^{\times} \mathrm{AR}=$ patient who had aortic regurgitation after Jatene operation.

Fig. 3 (right). The left ventricular end-diastolic internal dimension increased after pulmonary artery banding, but did not change after Jatene operation. Abbreviations are the same as those in previous figures.
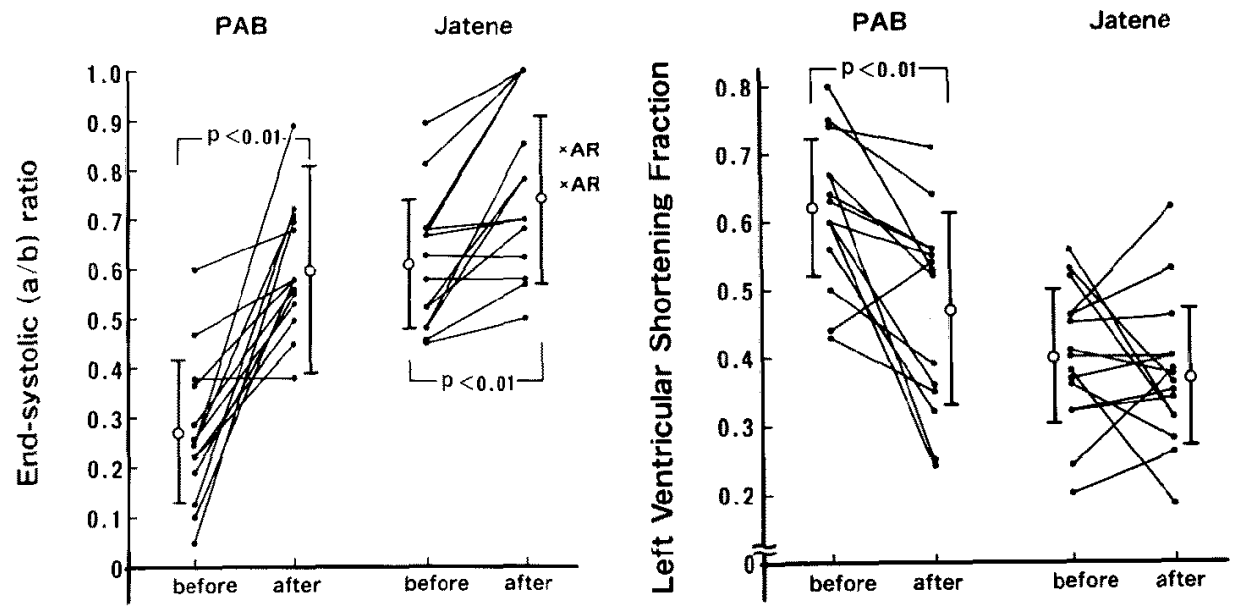

Fig. 4 (left). The end-systolic (a/b) ratio increased following either operation.

Fig. 5 (right). The left ventricular shortening fraction was reduced by pulmonary artery banding.

changed after the Jatene procedure (from $24.5 \pm 5.0$ to $25.0 \pm 3.0 \mathrm{~mm}$ ) (Fig. $3)$.

The $(\mathrm{a} / \mathrm{b}) \mathrm{s}$ ratio increased from $0.27 \pm 0.14$ to $0.60 \pm 0.21$ after pulmo- 

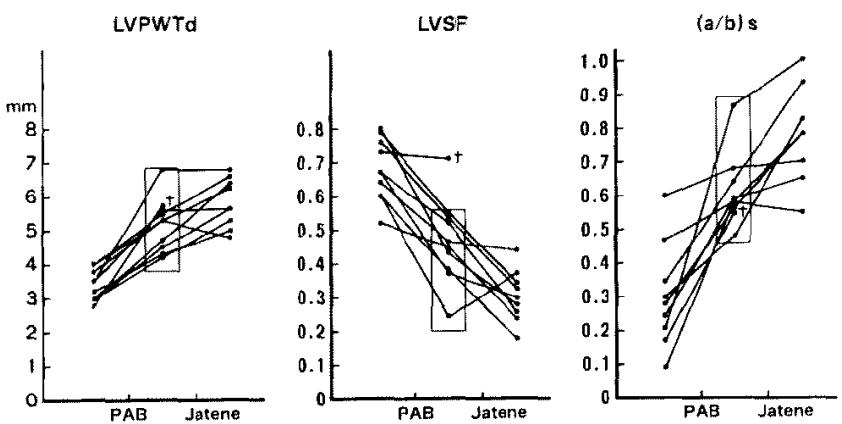

Fig. 6. The serial changes through $\mathrm{PAB}$ to Jatene operation are indicated for end-diastolic $L V$ posterior wall thickness, LV shortening fraction and the $(a / b)$ s ratio in 9 patients. $\dagger$ : a case who died early after Jatene operation.

nary artery banding and from $0.61 \pm 0.13$ to $0.74 \pm 0.17$ after the Jatene procedure (Fig. 4).

The LV shortening fraction decreased significantly following pulmonary artery banding from $0.62 \pm 0.10$ to $0.47 \pm 0.14$, but did not change after the Jatene procedure (from $0.40 \pm 0.10$ to $0.37 \pm 0.10$ ) (Fig. 5).

The serial changes through pulmonary artery banding to the Jatene procedure were observed in end-diastolic LV posterior wall thickness, LV shortening fraction, and the (a/b)s ratio (Fig. 6).

Nine patients who survived the Jatene procedure had satisfactory preoperative values. The one who did not survive the intracardiac repair had adequate LV wall thickness and (a/b)s ratio, but an excessively high shortening fraction. The left-to-right ventricular pressure ratio in this case measured at catheterization was 0.58 before surgery.

\section{Discussion}

The ultimate purpose of the present study was to determine the echocardiographic prerequisites for the Jatene procedure in complete TGA's, or at least to determine the timing of cardiac catheterization since invasive testing cannot be repeated frequently. We found that in our study survivors of the Jatene procedure had a diastolic $\mathrm{LV}$ posterior wall thickness of more than $3.5 \mathrm{~mm}$, an (a/b)s ratio larger than 0.44 , and an $L V$ shortening fraction of between 0.2 and 0.56 .

Bano-Radrigo et $\mathrm{al}^{5)}$ reported that in complete TGA's with an intact ventricular septum, the LV posterior wall thickness was normal at birth but decreased with age and became less than normal after 4 months of life. This 
was in agrecment with the present data showing that patients before pulmonary artery banding had an LV wall thickness below reported normal values. ${ }^{6,7)}$ Thus a preliminary procedure is performed in these patients ${ }^{1)}$ to increase the LV muscle mass. Our data show that pulmonary artery banding is effective for that purpose, and that the LV wall thickness is adequate for the arterial switch operation only 4 weeks after pulmonary artery banding.

End-diastolic LV internal dimension on M-mode echocardiography in complete TGA's with an intact ventricular septum is normal at birth but decreases to below normal after 1 month of life. ${ }^{81,9)}$ This is due to the leftward shift of the intraventricular septum because of the decreased LV pressure. Thus, it is assumed that, in the present study, the increase in LV wall thickness after pulmonary artery banding resulted from the increase of $L V$ pressure. As a matter of fact, LV wall thickness in all patients who successfully underwent the Jatene operation was within the normal range. Therefore, we can conclude that an end-diastolic LV posterior wall thickness of $4 \mathrm{~mm}$ is the lowest value at which the Jatene operation should be performed in children 16 months of age or younger.

We have already reported that the $(a / b) s$ ratio is useful for the cstimation of LV pressure in patients with complete TGA's." The increase in this parameter directly indicated the increase in $\mathrm{LV}$ pressure in patients who had undergone pulmonary artery banding. Following the Jatene operation, it increased further. This indicated that the right ventricular pressure decreased with or without a further increase of $L V$ pressure, since the $(a / b) s$ ratio represents the systolic right to left ventricular pressure ratio. Our previous data indicate that an (a/b)s ratio of 0.5 corresponds to an $\mathrm{LV}$ systolic pressure of approximately three fourths that of the systemic (right ventricular) pressure or about $60 \mathrm{mmHg}$. As Yacoub et al suggest, an LV pressure of 60 $\mathrm{mmHg}$ is the minimum requirement for the arterial switch operation. ${ }^{1)}$ In the present data our survivors of the Jatene operation had a ratio of 0.44 or higher, which corresponded to Yacoub's criterion. Therefore, it may be safe to conclude that an $(\mathrm{a} / \mathrm{b})$ s ratio of 0.5 or more is required for the Jatene operation.

The LV shortening fraction is affected not only by myocardial contractility but also by interventricular septal motion. In simple TGA's, the interventricular septum shifts backward during systole and forward during diastole in cases with low LV pressure, and for this reason it indicates an erroneously high value for the shortening fraction. Thus, the indication for the arterial switch operation should be determined very carefully.

We conclude that echocardiographic prerequisites for the Jatene operation are an end-diastolic LV wall thickness of greater than $4 \mathrm{~mm}$, an (a/b)s 
ratio of greater than 0.5 , and an LV shortening fraction of between 0.2 and 0.56 in patients younger than 16 months.

\section{REFERENCES}

1. Yacoub MH: Anatomic correction of transposition of the great arteries. Surgical technique. Ped Cardiol 4 (suppl 1): 61, 1983

2. Lecompte Y, Zannini L, Hazan E, Jarreau MM, Bex JP, Viet Tu T, Neveux JY: Anatomic correction of transposition of the great arteries. New technique without use of a prosthetic conduit. J Thorac Cardiovasc Surg 82: 629, 1981

3. Sahn DJ, DeMaria A, Kisslo J, Weyman A: Recommendations regarding quantitation in M-mode echocardiography. Results of a survey of echocardiographic measurements. Circulation 58 : 1072,1978

4. Satomi G, Nakamura K, Takao A, Imai Y: Two-dimensional echocardiographic detection of pulmonary venous channel stenosis after Senning's operation. Circulation 68: 545,1983

5. Bano-Radrigo A, Quero-Jineses M, Moreno-Granad F, Gamallo-Amat G: Wall thickness of ventricular chambers in transposition of the great arteries. Surgical implications. J Thorac Cardiovasc Surg 79: 592, 1980

6. Goldberg SJ, Allen HD, Sahn DJ: Pediatric and Adolescent Echocardiography, Yearbook Medical Publishers, Chicago, 1975

7. Ando M, Seguchi M, Mori K, Tooyama K, Tomimatsu H, Satomi G, Takao A: Echocardiographic measurement of various parameters of the left ventricle and aorta in normal Japanese children. JJMU Proceedings of the 44th Meeting, p 545, 1984

8. Huhta JC, Edwards WD, Fedlt RH, Puga FJ: Left ventricular wall thickness in complete transposition of the great arteries. I Thorac Cardiovasc Surg 84: 97, 1982

9. Maroto E, Fouron JC, Douste-Blazy MY, Carceller AM, Van Doesburg N, Kratz C: Influence of age and wall thickness, cavity dimensions and myocardial contractility of the left ventricle in simple transposition of the great arteries. Circulation 67:1311, 1983 